\title{
Effect of Magnetic Field on the Flow and Heat Transfer in a Casson Thin Film on an Unsteady Stretching Surface in the Presence of Viscous and Internal Heating
}

\author{
Nalleboyina Vijaya, Kata Sreelakshmi, Ganganapalli Sarojamma \\ Department of Applied Mathematics, Sri Padmavati Mahila Visvavidyalayam, Tirupati, India \\ Email: vijayanalleboyina@yahoo.co.in,katasreelakshmi@gmail.com,gsarojamma@gmail.com
}

How to cite this paper: Vijaya, N., Sreelakshmi, K. and Sarojamma, G. (2016) Effect of Magnetic Field on the Flow and Heat Transfer in a Casson Thin Film on an Unsteady Stretching Surface in the Presence of Viscous and Internal Heating. Open Journal of Fluid Dynamics, 6, 303-320. http://dx.doi.org/10.4236/ojfd.2016.64023

Received: November 4, 2016

Accepted: December 4, 2016

Published: December 7, 2016

Copyright $\odot 2016$ by authors and Scientific Research Publishing Inc. This work is licensed under the Creative Commons Attribution International License (CC BY 4.0).

http://creativecommons.org/licenses/by/4.0/

\begin{abstract}
The aim of this investigation is to analyze the effectiveness of Lorentz force, viscous dissipation and internal heating on the heat and flow characteristics of a non-Newtonian Casson fluid thin film resting on a stretching surface under the influence of a magnetic field. Employing suitable similarity variables and shooting technique and integrating scheme numerical solutions for velocity and temperature are obtained. The results of this analysis are compared with the published work and are found to be in good agreement. The thickness of the thin film is evaluated and is observed that Lorentz force and the non-Newtonian nature of the fluid have a thinning influence on the film. Velocity and temperature distributions in the thin film are discussed for various flow parameters.
\end{abstract}

\section{Keywords}

Unsteady Stretching Sheet, Casson Thin Film, Viscous Dissipation, Internal Heating

\section{Introduction}

During the recent years, study of liquid film flows has received significant attention from researchers due to its possible practical applications in several branches of science and technology. The characteristics of flow and heat transfer in a thin film are extremely useful to understand the coating process, design of different heat exchangers and chemical processing equipments. Similar situations prevail in wire and fiber coating, transpiration cooling, food stuff processing, reactor fluidization, manufacture of plastic and rubber sheets. Primary objective of all applications of extrusion is to maintain the 
surface quality of the final extrudate as best. It is reported that quality of the product depends on rate of heat transfer at the stretching surface. Hence, study of heat transfer under different thermal conditions shall be helpful to industry. Rassoulinejad-Mousavi and Abbasbandy [1] made an analytical study of forced convection in a circular tube filled with a Darcy-Brinkman-Forchheimer porous medium using spectral Homotopy analysis method. They studied the effect of high values of Forchheimer non-linear term on velocity, temperature and Nusselt number. Rassoulinejad-Mousavi et al. [2] examined the temperature and Nusselt number employing non-thermal equilibrium model in a PPC with permeable walls. Shahabeddin et al. [3] studied the effect of embedding aluminium porous metal foam inside the flow channels of an air-cooled lithium-ion battery to improve its thermal management. Several studies on boundary layer flows in a thin film in Newtonian fluids are available. Andersson et al. [4] explored the flow characteristics of an axisymmetric flow in a Newtonian film. A similar investigation in a liquid film on an unsteady stretching sheet was examined by Usha and Sridharan [5]. Wang [6] investigated the flow characteristics in a Newtonian thin liquid film on an unsteady stretching surface. This study was extended by Dandapat et al. [7] to include heat transfer analysis. Dandapat and Ray [8] [9] explored the flow characteristics in a thin liquid film on a rotating disk taking the effect of cooling and thermocapillarity into account. Study of electrically conducting fluid with heat transfer under the influence of a magnetic field has significant applications in several engineering problems such as re-entry of missiles, space crafts, MHD generators, devices in petroleum industry, nuclear reactors, astro physical flows and the boundary layer control. Gailitis and Lielausis [10] mentioned the effects of Lorentz force on controlling flow of an electrically conducting fluids flowing over a flat plate utilizing an external electromagnetic field with ordering electrodes and permanent magnates with alternating polarity and magnetization. Shirazpour et al. [11] investigated the fully developed flow of a viscous fluid in a porous saturated channel under the influence of Lorentz force using the Darcy-Brinkman model. Analytical solutions are obtained employing Homotopy perturbation method. Rassoulinejad-Mousavi et al. [12] made a theoretical study of the temperature and Nusselt number of a conducting Maxwell fluid through a porous saturated parallel plates channel with different boundary conditions using non-thermal equilibrium model. Lin et al. [13] explored the flow and heat transfer of MHD pseudo-plastic nanofluid in a finite film over a stretching surface with internal heating effects.

The effect of viscous dissipation in heat transfer problems is of importance as it plays significant role as an energy source. The presence of viscous dissipation affects both the temperature and heat transfer rates. Rassoulinejad-Mousavi and Hessameddin [14] explored the effect of quadratic drag on viscous dissipation in a fluid saturated porous medium through a channel bounded by two isothermal or isoflux walls. They observed that the Nusselt number is sensitive to the Forchheimer number. The study of viscous heating in thin film flows has considerable interest. For example, in polymer processing flows like injection modelling or extrusion at high rates and aerodynamic heating in the thin layer around a high speed aircraft, the temperature is observed to increase 
prominently. Vajravelu et al. [15] carried out a mathematical analysis of the effects of thermo physical properties on the thin film flow of an Ostwald-de Waele liquid over a stretching surface in the presence of viscous dissipation. Abel et al. [16] examined the effect of viscous dissipation on the MHD flow and heat transfer in a liquid film due to a stretching surface. Krishna Jyothi et al. [17] analysed the effect of viscous dissipation on the unsteady boundary layer flow of an incompressible, viscous electrically conducting fluid over a sheet that stretches exponentially in the presence of temperature dependent heat source and thermophoresis with chemical reaction. Sarojamma et al. [18] presented a mathematical model to study the effect of viscous dissipation on the time dependent flow of a Casson fluid due to a stretching sheet embedded in a rotating fluid subject to a uniform magnetic field, with thermal radiation and chemical reaction of nth order.

In industry free surface flows of non-Newtonian fluids in thin films are frequently encountered in industry especially in polymer and plastic fabrication and in coating equipment. It is well known that the process of protective coatings on an extrudate use paints or fluids that are generally non-Newtonian in nature. Studies on film flow of power-law fluids have been examined by several researchers [19] [20] [21] [22].

However, studies on flows in Casson fluid film are very limited in literature. Casson fluid is a non-Newtonian fluid that can be described as a shear thinning fluid having an infinite viscosity at zero shear rates and a yield stress with no flow below this critical yield value. The empirical model was suggested by Casson [23] while analyzing the flow curves of suspensions of pigments in lithographic varnishes. It is reported that Casson's constitutive equation described accurately the silicon suspensions [24], suspensions of bentonite in water [25] and many other industrial polymers. It is well established that when blood flows through small vessels its behavior is satisfactorily explained by modeling it as a Casson fluid. It is reported that blood flow affects the thermal response of living tissues. Craciunescu and Clegg [26] studied the oscillatory flow of heat transfer in blood flow considering the vessels of blood as rigid. Weinbaun et al. [27] and Jiji et al. [28] studied the heat transfer under the influence of vascular microstructure on surface tissue. Cavaliere [29] examined the heat supply to tumors in human beings in the extremities by local perfusion with warm blood. Sarojamma et al. [30] explored the characteristics of heat and mass transfer on the MHD boundary layer flow of a Casson fluid over stretching surface under the influence of a magnetic field. Megahed [31] examined the impact of variable heat flux, viscous heating and velocity slip flow on the heat transfer of a Casson fluid in thin film on a stretching sheet.

In this paper, influence of magnetic field on the thin film flow and heat transfer of a Casson fluid over an unsteady stretching sheet is investigated. The effects of viscous dissipation and internal heating are taken into consideration. Application of suitable similarity variables reduced the governing PDEs into a set of coupled non-linear ODEs for which numerical solutions have been obtained. To the best of knowledge of the authors, influence of transverse magnetic field, viscous dissipation and internal heating on the flow and heat transfer of a Casson fluid film over an unsteady stretching has not yet 
been studied in literature.

\section{Mathematical Formulation}

Consider a conducting incompressible non-Newtonian Casson thin film over a heated elastic sheet that emerges from a narrow slit at the origin of the Cartesian coordinate system for investigations as shown schematically in Figure 1. A thin film of uniform thickness $h(t)$ lies on the horizontal stretching sheet. Liquid motion within the film is caused by stretching sheet.

The continuous sheet is parallel to $\mathrm{x}$-axis and moves in its own plane with a velocity

$$
U(x, t)=\frac{b x}{1-\alpha t}
$$

where $\alpha$ and $b$ are positive constants with dimension per time. The elastic sheet's temperature $T_{s}$ is assumed to vary with the distance $x$ from the slit as

$$
T_{s}(x, t)=T_{0}-T_{\text {ref }}\left[\frac{b x^{2}}{2 v}\right](1-\alpha t)^{-3 / 2}
$$

where $T_{0}$ is the temperature at the slit, $v$ is the kinematic viscocity, $T_{\text {ref }}$ is the constant reference temperature such that $0 \leq T_{\text {ref }} \leq T_{0} \forall t<\frac{1}{\alpha}$. A transverse magnetic field $B=B_{0}(1-\alpha t)^{-1 / 2}$ is applied to the thin liquid film.

The constitutive of the Casson fluid can be written as [32]

$$
\tau_{i j}=\left\{\begin{array}{l}
2\left(\mu_{B}+\frac{P_{y}}{\sqrt{2 \pi}}\right) e_{i j}, \pi>\pi_{c} \\
2\left(\mu_{B}+\frac{P_{y}}{\sqrt{2 \pi_{c}}}\right) e_{i j}, \pi<\pi_{c}
\end{array}\right.
$$

where $\tau_{i j}$ is the $(i, j)^{\text {tho }}$ component of the stress tensor, $\mu_{B}$ is the plastic dynamic viscosity of the non-Newtonian fluid, $P_{y}$ is the yield stress of the fluid, $\pi$ is the product of the component of deformation rate with itself, namely, $\pi=e_{i j} e_{i j}$, and $e_{i j}$ is the $(i, j)^{\text {tho }}$ component of deformation rate, and $\pi_{c}$ is critical value of $\pi$ based

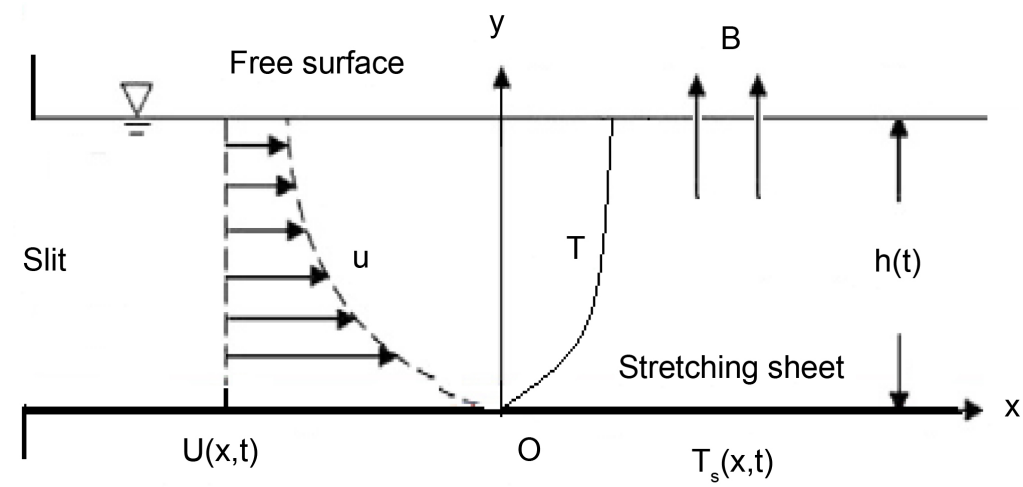

Figure 1. Physical model and coordinate system. 
on non-Newtonian model.

Under these assumptions, the motion of liquid film due to stretching is governed by

$$
\begin{gathered}
\frac{\partial u}{\partial x}+\frac{\partial v}{\partial y}=0 \\
\frac{\partial u}{\partial t}+u \frac{\partial u}{\partial x}+v \frac{\partial u}{\partial y}=v\left(1+\frac{1}{\beta}\right) \frac{\partial^{2} u}{\partial y^{2}}-\frac{\sigma B^{2}}{\rho} u \\
\rho c_{p}\left(\frac{\partial T}{\partial t}+u \frac{\partial T}{\partial x}+v \frac{\partial T}{\partial y}\right)=k \frac{\partial^{2} T}{\partial y^{2}}+\mu\left(1+\frac{1}{\beta}\right)\left(\frac{\partial u}{\partial y}\right)^{2}+Q
\end{gathered}
$$

where $u$ and $v$ are velocity components of liquid in $\mathrm{x}$ - and y-directions, $T$ is temperature, $v$ is kinematic viscosity, $\mu$ is dynamic viscosity, $\rho$ is density, $c_{p}$ is specific heat at constant pressure, $k$ is the thermal conductivity, $\beta=\mu_{B} \sqrt{2 \pi_{c}} / P_{y}$ is the Casson parameter and $\sigma$ is electrical conductivity.

The term $Q$ is heat generation $(>0)$ or absorption $(<0)$ per unit volume which is modeled as [33]

$$
Q=\frac{k U}{x \nu} B^{*}\left(T-T_{0}\right)
$$

where $B^{*}$ is temperature-dependent heat generation/absorption and is positive in case of the elastic sheet's generation of heat and negative in case of the sheet's absorption of heat from the fluid flow.

The boundary conditions on the stretching sheet are no slip, no penetration and imposed sheet temperature distribution and they are represented respectively as

$$
\begin{gathered}
u=U, v=0, T=T_{s} \text { at } y=0, \\
\frac{\partial u}{\partial y}=0, \frac{\partial T}{\partial y}=0, v=\frac{\mathrm{d} h}{\mathrm{~d} t} \text { at } y=h(t)
\end{gathered}
$$

The following similarity transformation are introduced

$$
\begin{gathered}
\eta=\left[\frac{b}{v(1-\alpha t)}\right]^{\frac{1}{2}} y, \psi=x\left[\frac{v b}{1-\alpha t}\right]^{\frac{1}{2}} f(\eta), \\
T=T_{0}-T_{r e f}\left[\frac{b x^{2}}{2 v(1-\alpha t)^{3 / 2}}\right] \theta(\eta), \quad \theta(\eta)=\frac{T-T_{0}}{T_{S}-T_{0}},
\end{gathered}
$$

Also, $\psi(x, y)$ is the stream function which automatically assures mass conversation Equation (4). The velocity components are readily obtained as

$$
u=\frac{\partial \psi}{\partial y}=\frac{b x}{1-\alpha t} f^{\prime}(\eta) \quad v=-\frac{\partial \psi}{\partial x}=-\left(\frac{v b}{1-\alpha t}\right)^{1 / 2} f(\eta)
$$

where prime denotes differentiation with respect to $\eta$. Thus the mathematical problem defined through Equations (4)-(9) are transformed to the following non-linear boundary value problem on the finite range of $0-1$ :

$$
\left(1+\frac{1}{\beta}\right) f^{\prime \prime \prime}+\left[f f^{\prime \prime}-S\left(f^{\prime}+\frac{\eta}{2} f^{\prime \prime}\right)-f^{\prime 2}-M f^{\prime}\right]=0
$$




$$
\theta^{\prime \prime}+\operatorname{Pr}\left(f \theta^{\prime}-2 f^{\prime} \theta-\frac{S}{2}\left(\eta \theta^{\prime}+3 \theta\right)+E c\left(1+\frac{1}{\beta}\right) f^{\prime \prime 2}\right)+B^{*} \theta=0
$$

Subject to the boundary conditions

$$
\begin{gathered}
f(0)=0, f^{\prime}(0)=1, \theta(0)=1, \\
f(\gamma)=\frac{1}{2} S \gamma, f^{\prime \prime}(\gamma)=0, \theta^{\prime}(\gamma)=0
\end{gathered}
$$

where $S=\alpha / b$ is the dimensionless measure of unsteadiness, $M=\sigma B_{0}^{2} / \rho b$ is Magnetic field parameter, $\operatorname{Pr}=\rho c_{p} v / k$ is Prandtl number and $E c=U^{2} / c_{p}\left(T_{s}-T_{0}\right)$ is Eckert number. Further, $\gamma$ denotes the value of the similarity variable $\eta$ at the free surface so that the first term of Equation (10) gives

$$
\gamma=\left(\frac{b}{v(1-\alpha t)}\right)^{1 / 2} h(t)
$$

Since $\gamma$ is an unknown constant, which should be determined, as a whole, from the set of the present boundary-value problem, the rate of change of the film thickness can be obtained as follows:

$$
\frac{\mathrm{d} h}{\mathrm{~d} t}=-\frac{\alpha \gamma}{2}\left(\frac{v}{b(1-\alpha t)}\right)^{1 / 2}
$$

Thus, the kinematic constraint at $y=h(t)$ given by Equation (9) transforms to the free surface condition (17).

The parameters of engineering interest in heat transfer problems are Skin friction coefficient $C_{f x}$ and Nusselt number $N u_{x}$. These parameters characterize surface drag and heat transfer rate and are defined respectively, as

$$
\begin{gathered}
C_{f x} \operatorname{Re}_{x}^{1 / 2}=-2\left(1+\frac{1}{\beta}\right) f^{\prime \prime}(0) \\
N u_{x} \operatorname{Re}_{x}^{-1 / 2}=\theta^{\prime}(0)
\end{gathered}
$$

where $\operatorname{Re}_{x}=U x / v$ is the local Reynolds number.

The coupled ordinary differential Equations (13) and (14) are non linear and exact analytical solutions are not possible. Equations (13) and (14) with the pertinent boundary conditions (15) and (16) are solved numerically by the most efficient numerical shooting technique with fourth order Runge-Kutta algorithm. First we convert these equations into a set of first order equations as follows:

$$
\begin{gathered}
\frac{\mathrm{d} f_{0}}{\mathrm{~d} \eta}=f_{1}, \quad \frac{\mathrm{d} f_{1}}{\mathrm{~d} \eta}=f_{2},\left(1+\frac{1}{\beta}\right) \frac{\mathrm{d} f_{2}}{\mathrm{~d} \eta}=S\left(f_{1}+\frac{\eta}{2} f_{2}\right)+f_{1}^{2}-f_{0} f_{2}+M f_{1}, \\
\frac{\mathrm{d} \theta_{0}}{\mathrm{~d} \eta}=\theta_{1}, \quad \frac{\mathrm{d} \theta_{1}}{\mathrm{~d} \eta}=\operatorname{Pr}\left(\frac{S}{2}\left(3 \theta_{0}+\eta \theta_{1}\right)+2 \theta_{0} f_{1}-\theta_{1} f_{0}-E c\left(1+\frac{1}{\beta}\right) f_{2}^{2}\right)-B^{*} \theta_{0} .
\end{gathered}
$$

Corresponding boundary conditions take the form,

$$
f_{0}(0)=0, f_{1}(0)=1, \quad \theta_{0}=1 \text {, }
$$




$$
f_{0}(\gamma)=\frac{1}{2} S \gamma, f_{2}(\gamma)=0, \theta_{1}(\gamma)=0
$$

Here $f_{0}(\eta)=f(\eta)$ and $\theta_{0}(\eta)=\theta(\eta)$. This warrants the initial values of $f_{2}(0)$ and $\theta_{1}(0)$ and hence suitable guess values are chosen and subsequently integration is performed. A step size of $\Delta \eta=0.01$ is chosen. It is required to estimate the value of $\gamma$ satisfying the boundary condition $f_{0}(\gamma)=\frac{S \gamma}{2}$. Hence, it is essential to iterate the value of $\gamma$ until it satisfies this condition with an error of tolerance of $10^{-6}$. Accuracy of the present scheme is ensured by comparing the present results, viz., non dimensional thickness of the film $\gamma$, surface skin friction coefficient $f^{\prime \prime}(0)$ with the corresponding values evaluated by Wang [6], Abel et al. [34] and Megahed [31] in the absence of magnetic field parameter and $\beta \rightarrow \infty$ for different values of unsteady parameter. It is pertinent to mention that, as Wang [6] used different similarity variables, the values of $f^{\prime \prime}(0) / \gamma$ obtained by Wang [6], shall be same as $f^{\prime \prime}(0)$ of the present paper. These values are presented in Table 1 and it is seen that they are an excellent agreement.

\section{Results and Discussion}

The coupled non-linear differential Equations (13) and (14) along with the appropriate boundary conditions (15) and (16) are numerically solved employing the BVP4C technique. In order to have a physical insight of the flow in the thin film, numerical computations of flow variables for various sets of governing parameters have been carried out and graphically presented.

Variation of film thickness versus magnetic field parameter for different values of the unsteadiness parameter is plotted in Figure 2. It may be concluded that film becomes thinner for increasing values of $S$. Film thickness reduces rapidly for smaller values of magnetic field, and for higher values, a further reduction is noticed. However, this reduction is steady.

Behavior of free surface velocity $f^{\prime}(\beta)$ versus magnetic field for different values of

Table 1. Comparison of $\gamma$ and $f^{\prime \prime}(0)$ with published values when $M=0$ and $\beta \rightarrow \infty$ for various values of $S$.

\begin{tabular}{ccccccccc}
\hline & \multicolumn{2}{c}{ Wang [6] } & \multicolumn{2}{c}{ Abel et al. [34] } & \multicolumn{2}{c}{ Megahed [31] } & \multicolumn{2}{c}{ Present study } \\
\cline { 2 - 8 } & $\gamma$ & $f^{\prime \prime}(0) / \gamma$ & $\gamma$ & $f^{\prime \prime}(0)$ & $\gamma$ & $f^{\prime \prime}(0)$ & $\gamma$ & $f^{\prime \prime}(0)$ \\
\hline 0.4 & 5.122490 & -1.307785 & 4.981455 & -1.134098 & 4.98145 & -1.134096 & 4.981455 & -1.134098 \\
0.6 & 3.131250 & -1.195155 & 3.131710 & -1.195128 & 3.131710 & -1.195126 & 3.131710 & -1.195128 \\
0.8 & 2.151990 & -1.245795 & 2.151990 & -1.245805 & 2.151994 & -1.245806 & 2.151990 & -1.245805 \\
1.0 & 2.543620 & -1.277762 & 1.543617 & -1.277769 & 1.543616 & -1.277769 & 1.543617 & -1.277769 \\
1.2 & 1.127780 & -1.279177 & 1.127780 & -1.279171 & 1.127781 & -1.279172 & 1.127780 & -1.279171 \\
1.4 & 0821032 & -1.233549 & 0.821033 & -1.233545 & 0.821032 & -1.233545 & 0.821033 & -1.233545 \\
1.6 & 0.576173 & -1.491137 & 0.576176 & -1.114937 & 0.576173 & -1.114938 & 0.576176 & -1.114937 \\
1.8 & 0.356389 & -0.867414 & 0.356390 & -0.867416 & 0.356389 & -0.867414 & 0.356390 & -0.867416 \\
\hline
\end{tabular}


unsteadiness parameter is highlighted in Figure 3. It is evident from this figure that free surface velocity remains almost uniform for all values of the magnetic field. As unsteadiness parameter $S$ increases the free surface velocity decreases. When $S$ changes its value from 0.8 to 1.2 there is a twofold reduction in free surface velocity.

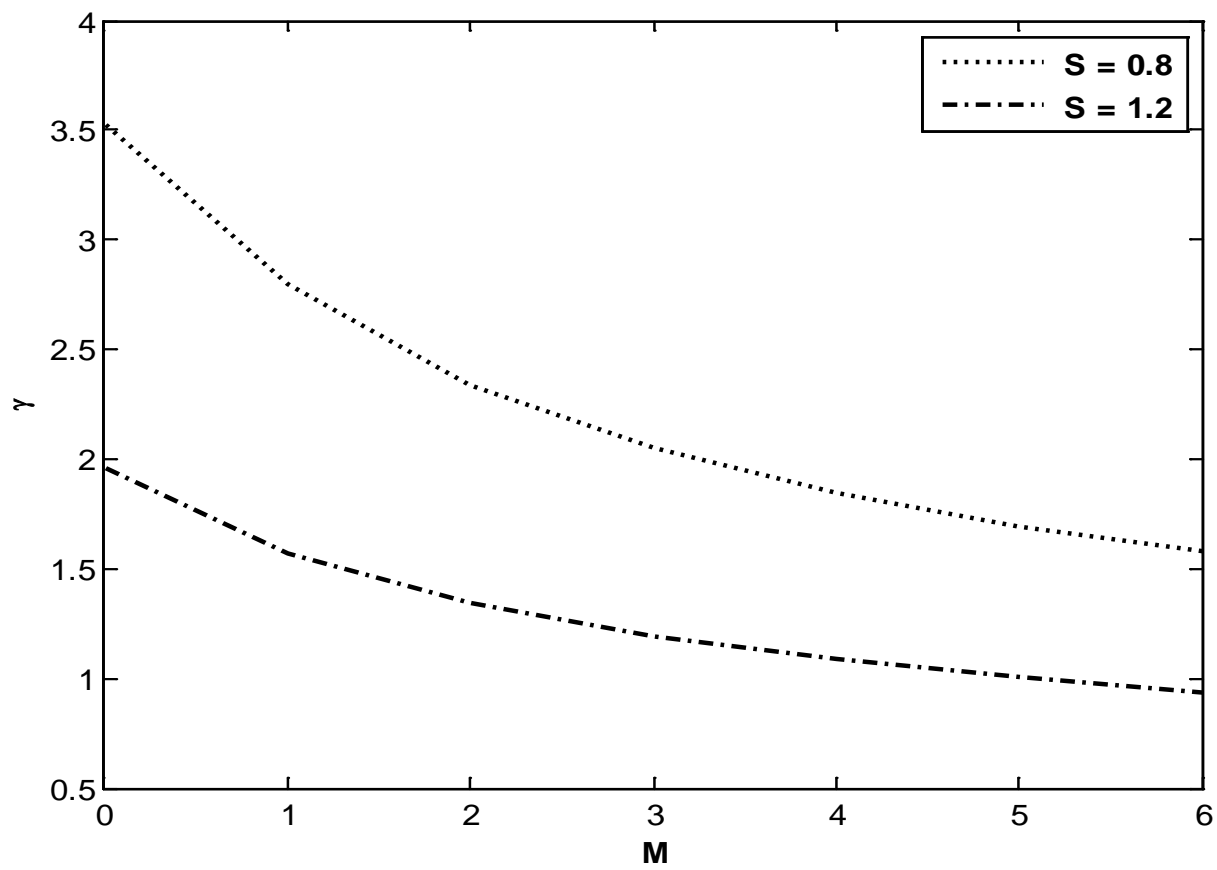

Figure 2. Variation of film thickness $\gamma$ with $M$.

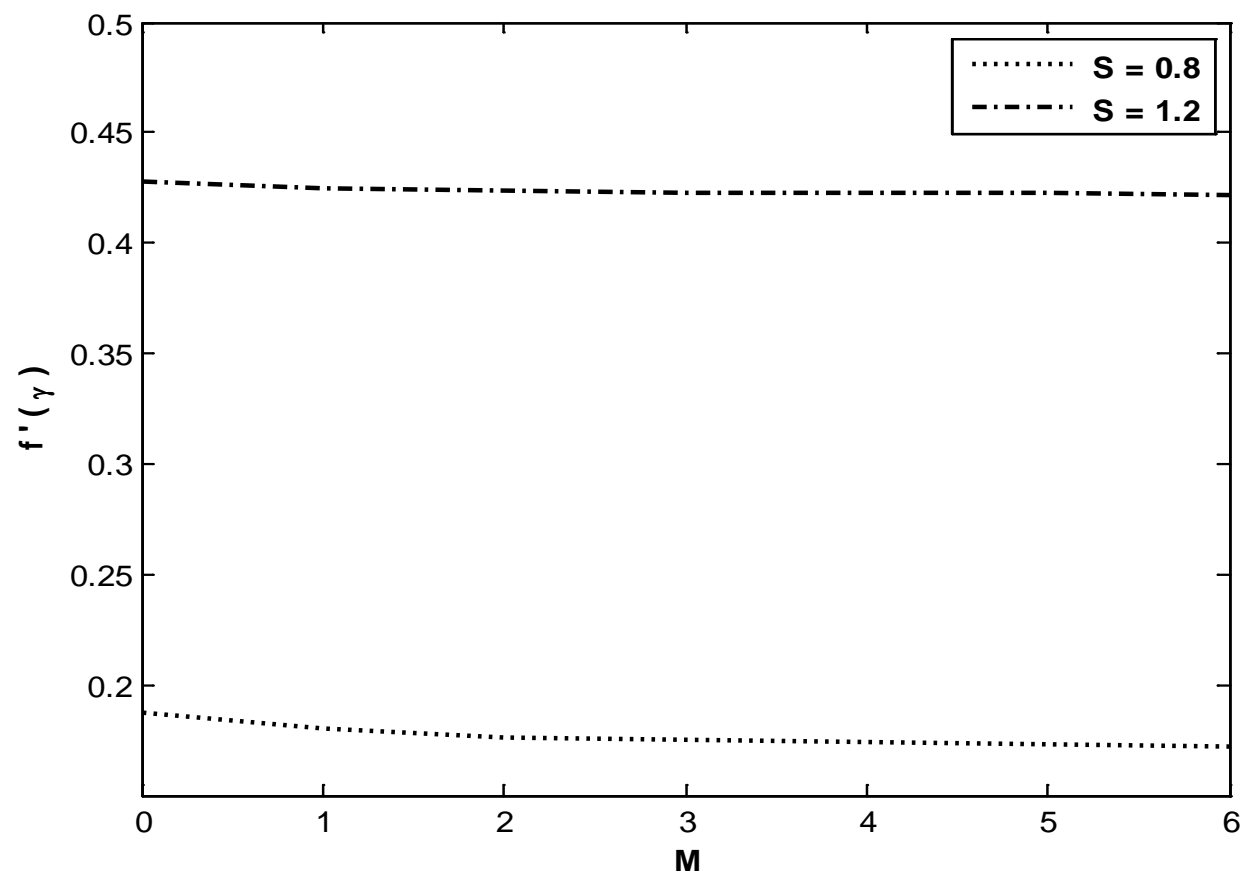

Figure 3. Variation of free surface velocity $f^{\prime}(\gamma)$ with $M$. 
Figure 4 illustrates the influence of magnetic field and unsteadiness on free surface temperature. It is clear that free surface temperature increases as unsteadiness parameter increases. When $S=1.2$ free surface temperature increases monotonically with increasing values of $M$ while for $S=0.8$ it increases linearly with $M$.

Figure 5 and Figure 6 are the plots of velocity and temperature respectively for a

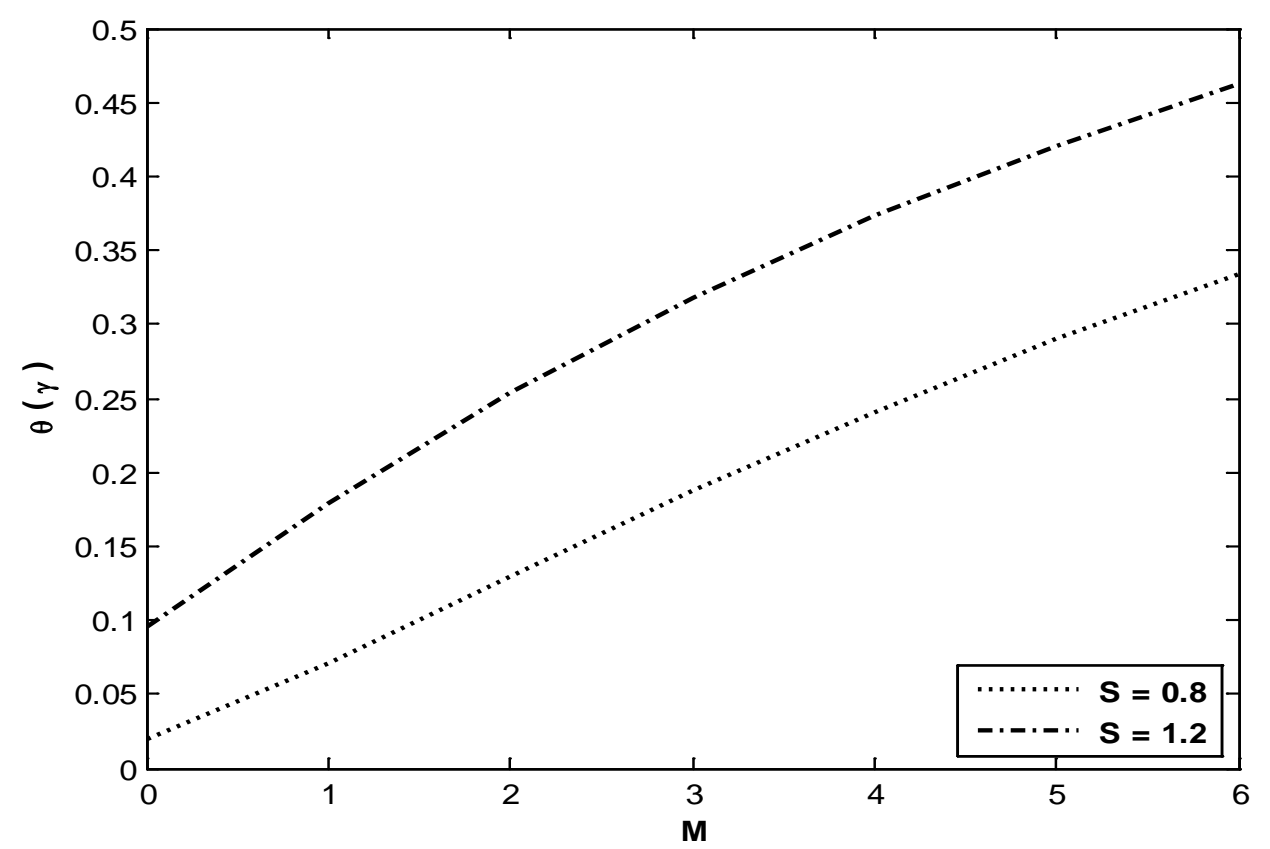

Figure 4. Variation of free surface temperature $\theta(\gamma)$ with $M$.

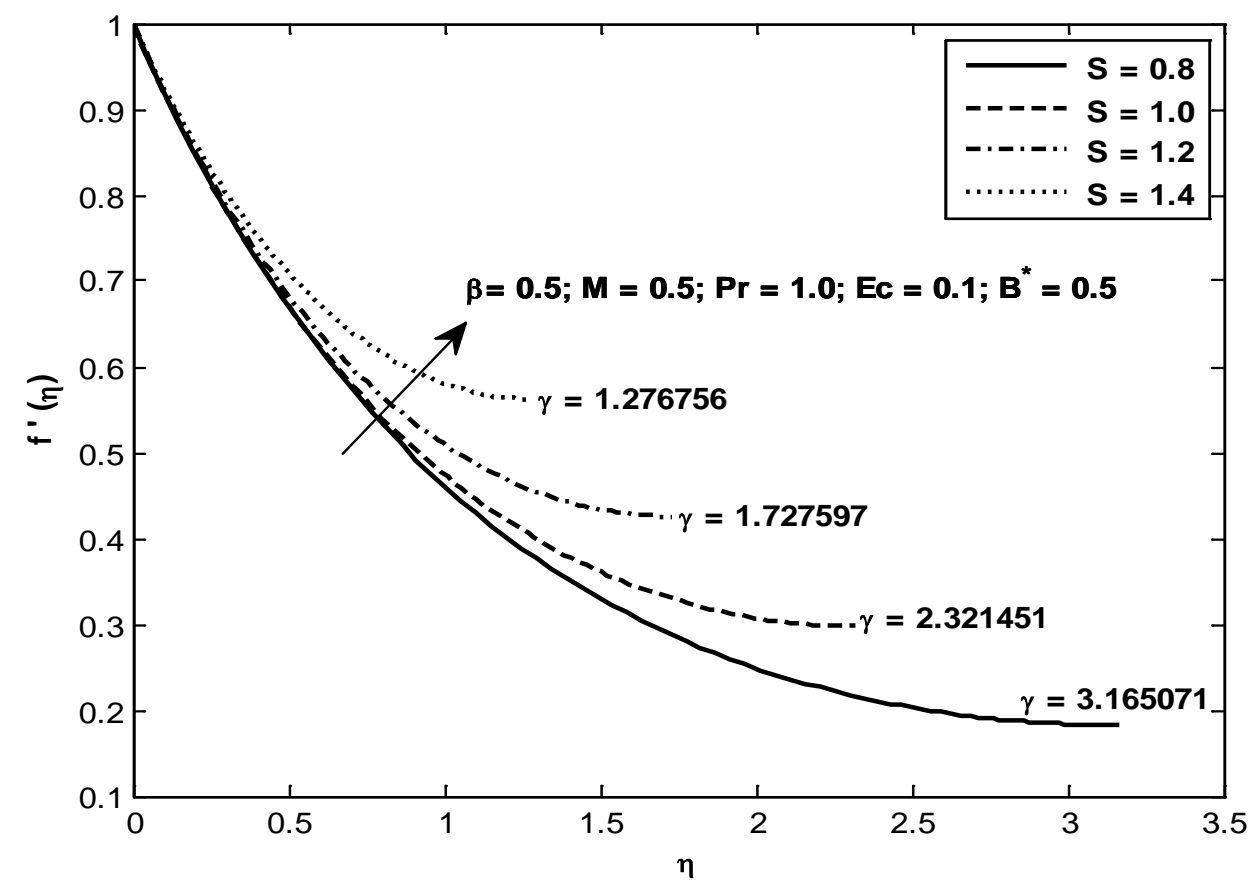

Figure 5. Velocity profiles for different values of $S$. 


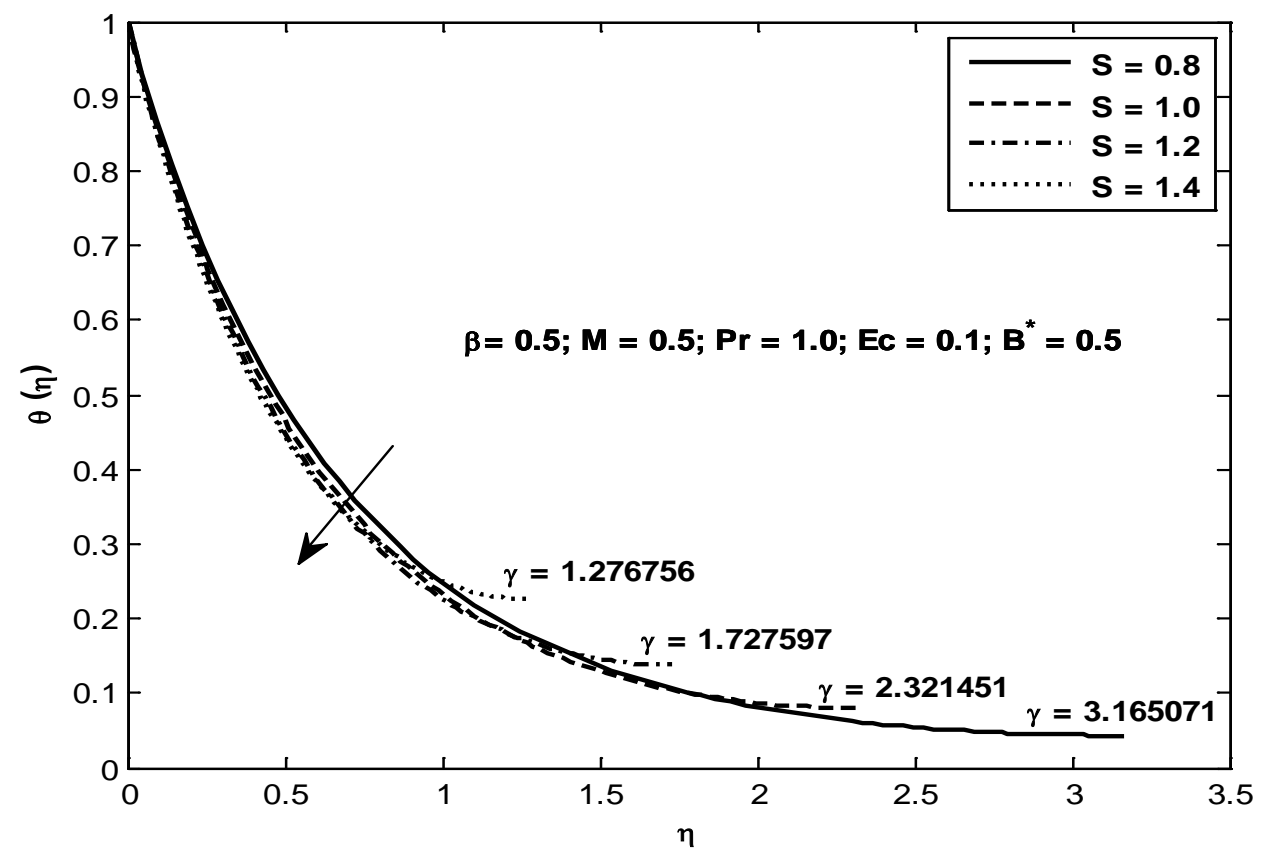

Figure 6. Temperature profiles for different values of $S$.

variation of unsteadiness parameter $S$. It is observed that velocity distribution in the film decreases monotonically for small values of unsteadiness parameter. As the unsteadiness parameter takes higher values fluids gets accelerated and hence higher velocities occur. Films become thinner for increasing values of unsteadiness parameter. When unsteadiness parameter $S=1.4$, film thickness is reduced by two and half times than that of the film corresponding to $S=0.8$. Fluid in the film gets cooled as unsteadiness parameter increases. However, reduction in the temperature is small.

Figure 7 and Figure 8 highlight the impact of strength of magnetic field on the velocity and temperature distributions in the film. In the absence of magnetic field, velocity steadily decreases in the film. Presence of magnetic field causes a rapid reduction of velocity in the vicinity of the boundary due to the action of Lorentz force which resists the fluid flow. Temperature shows an opposite behavior with a gradual enhancement in temperature for increasing values of the magnetic parameter $M$. For all values of $M$, temperature assumes its minimum value at the free surface.

Figure 9 and Figure 10 illustrate the influence of non-Newtonian nature of the fluid through the Casson parameter on velocity. It is observed that velocity in the vicinity of the boundary becomes a constant function of the Casson parameter. However, a significant reduction in the velocity in the film is observed away from the boundary for increasing values of $\beta$. Reduction in the velocity might be due to the non-Newtonian nature of the fluid as increase in Casson parameter corresponds to an increase in the plastic dynamic viscosity of the fluid. Film thickness also gets reduced for higher values of $\beta$. However, increasing values of $\beta$ raise the temperature.

Figure 11 presents the plots of temperature for a variation in Prandtl number. It is revealed that temperature drops from its higher value on the wall to its minimum value 


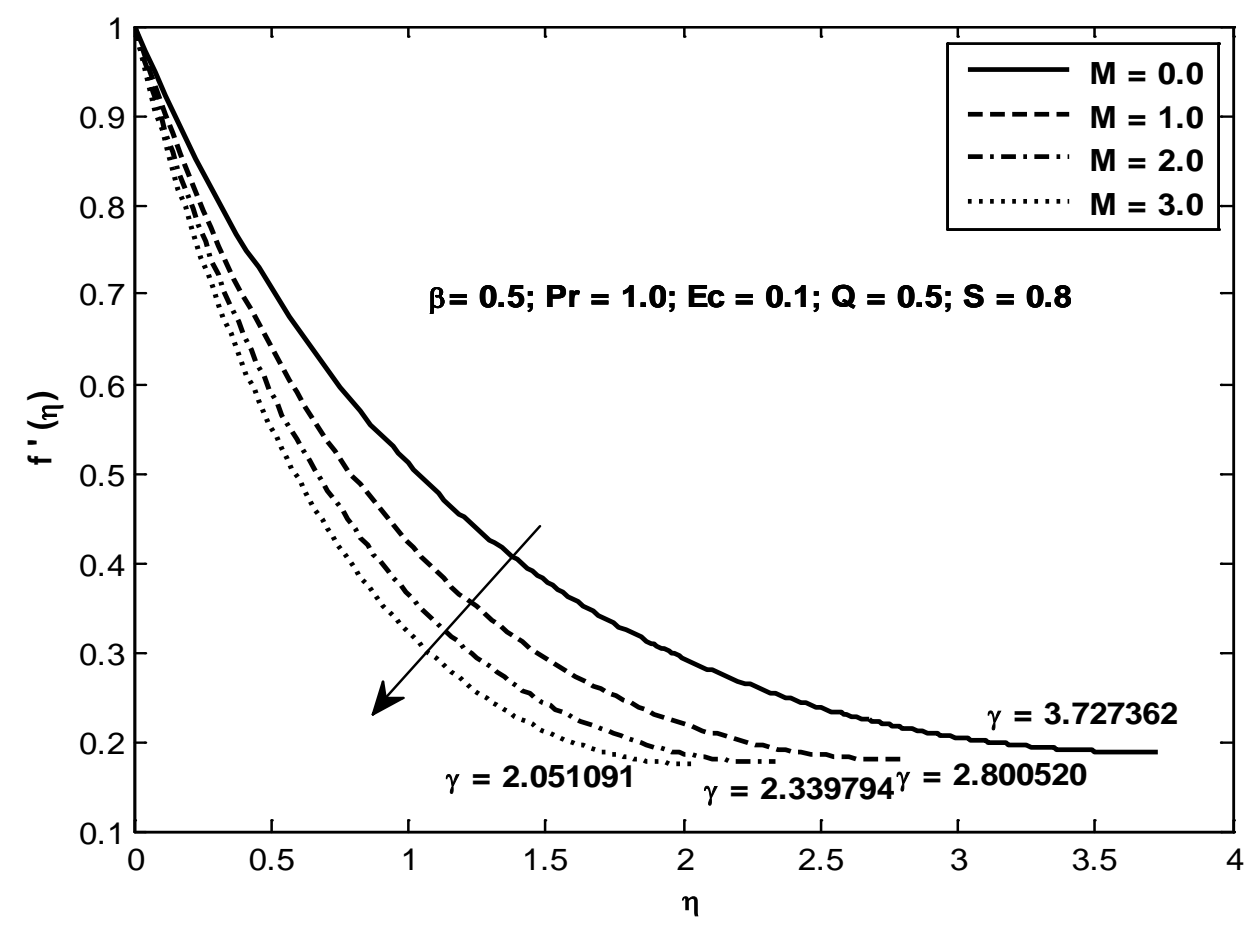

Figure 7. Velocity profiles for different values of $M$.

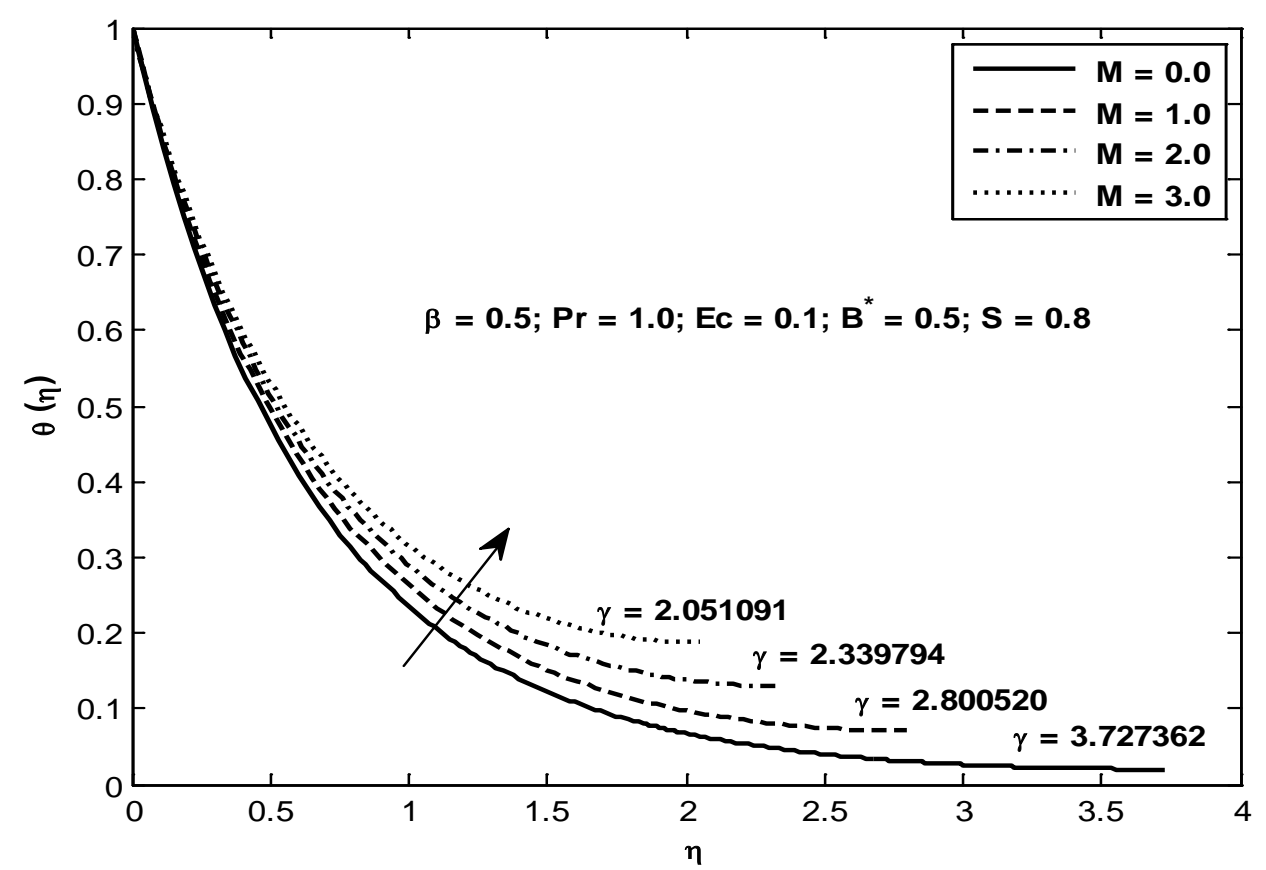

Figure 8. Temperature profiles for different values of $M$.

on the surface. For higher values of $\operatorname{Pr}$, temperature falls rapidly near the boundary. When $\operatorname{Pr} \geq 2$ it attains zero temperature at $\eta=2.5$. Higher values of $\operatorname{Pr}$ indicate that thermal conductivity of the corresponding fluid is lower.

Figure 12 illustrates the impact of Eckert number on temperature. Temperature plots 


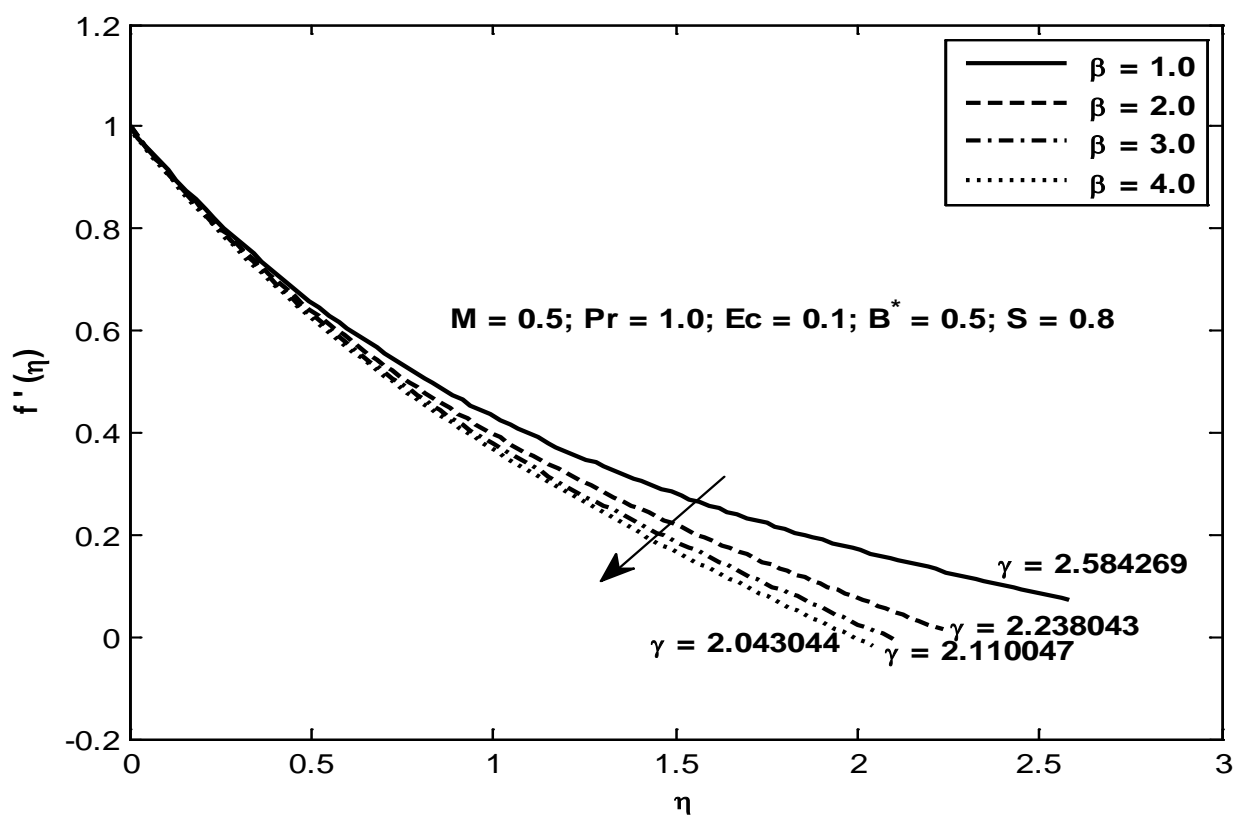

Figure 9. Velocity profiles for different values of $\beta$.

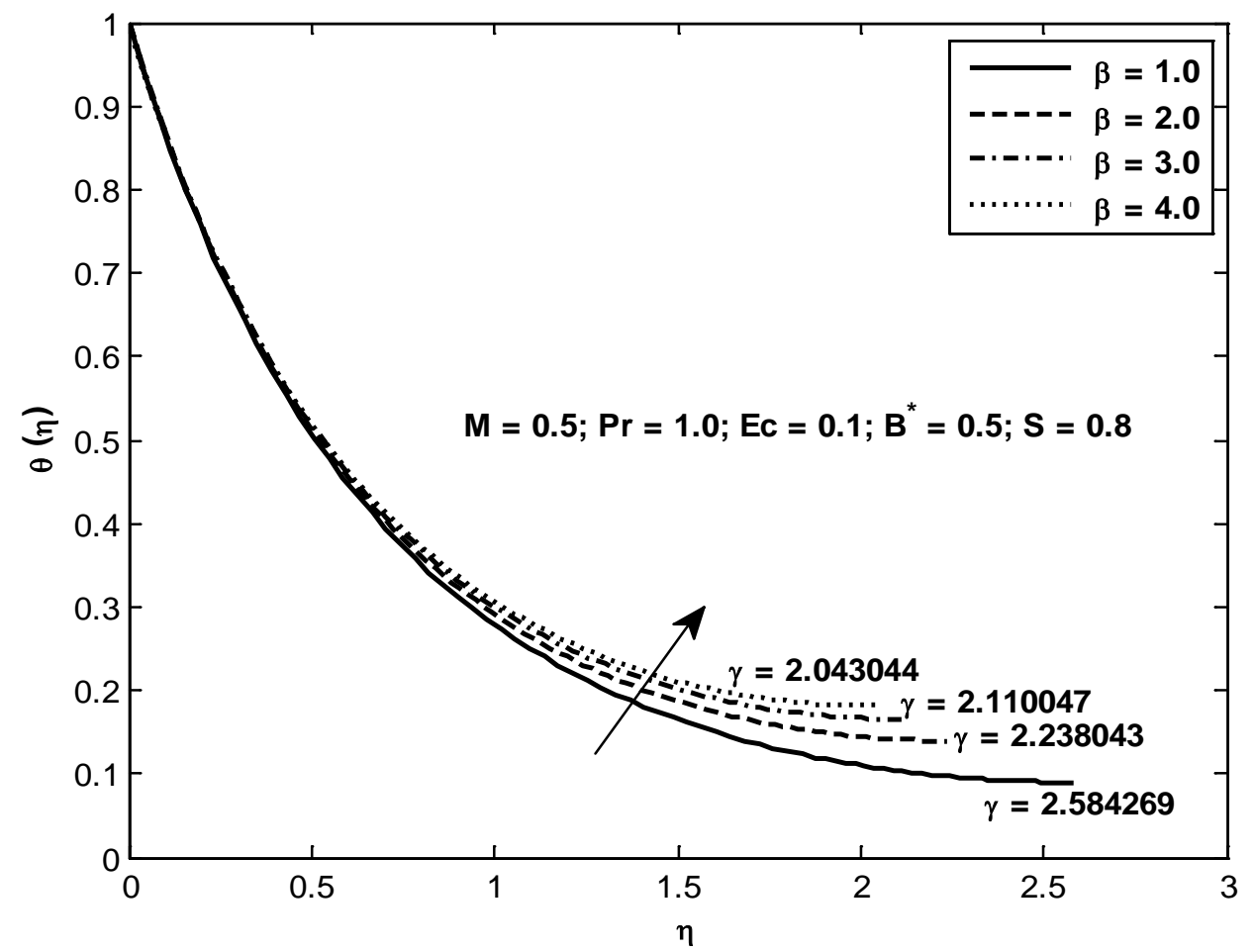

Figure 10. Temperature profiles for different values of $\beta$.

indicate that increasing values of $E c$ heat up the fluid in the film resulting in higher temperatures. This enhancement is due to internal heating in the fluid layers. In particular near the boundary when $E c=3.0$ there is an over shot of the temperature. As illustrated in Figure 13, the presence of heat source $\left(B^{*}>0\right)$, increases temperature while 


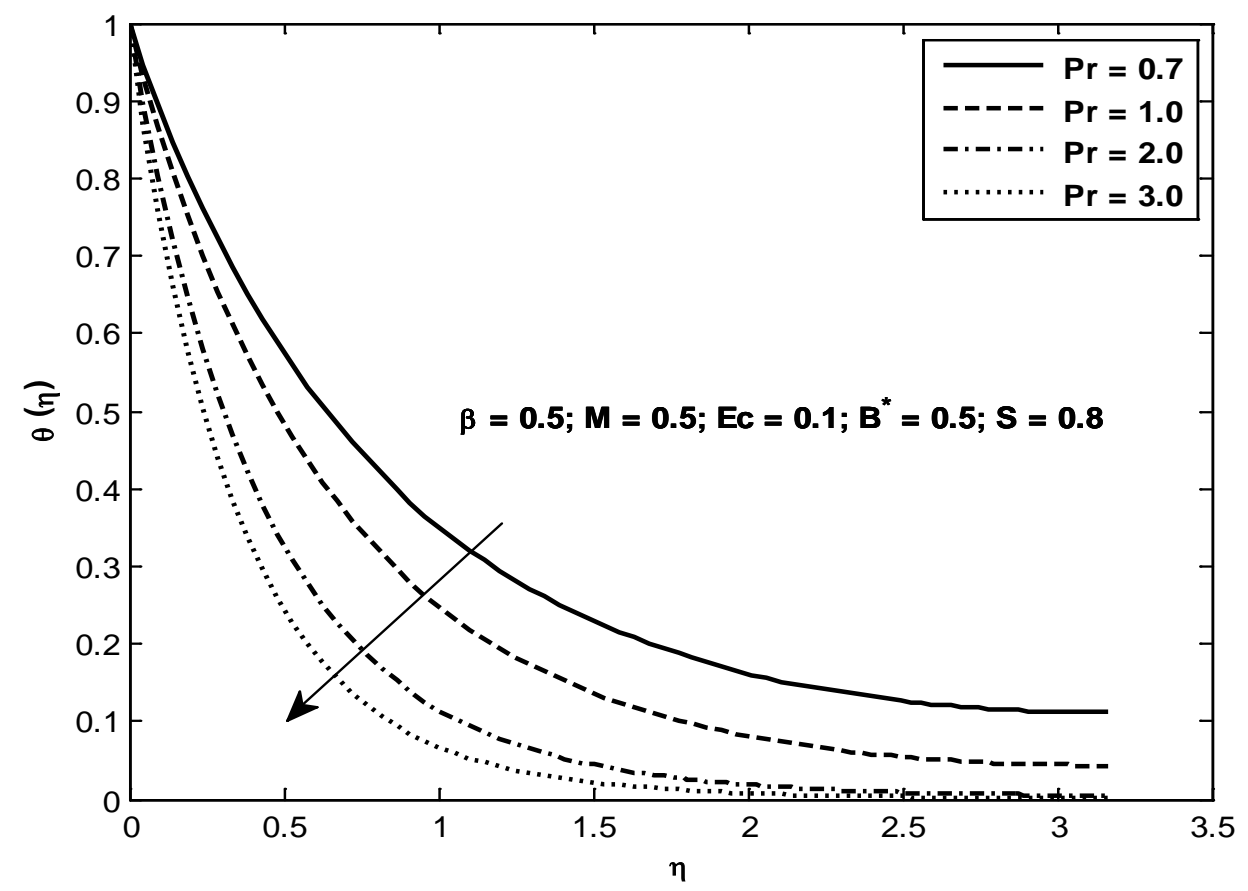

Figure 11. Temperature profiles for different values of $P r$.

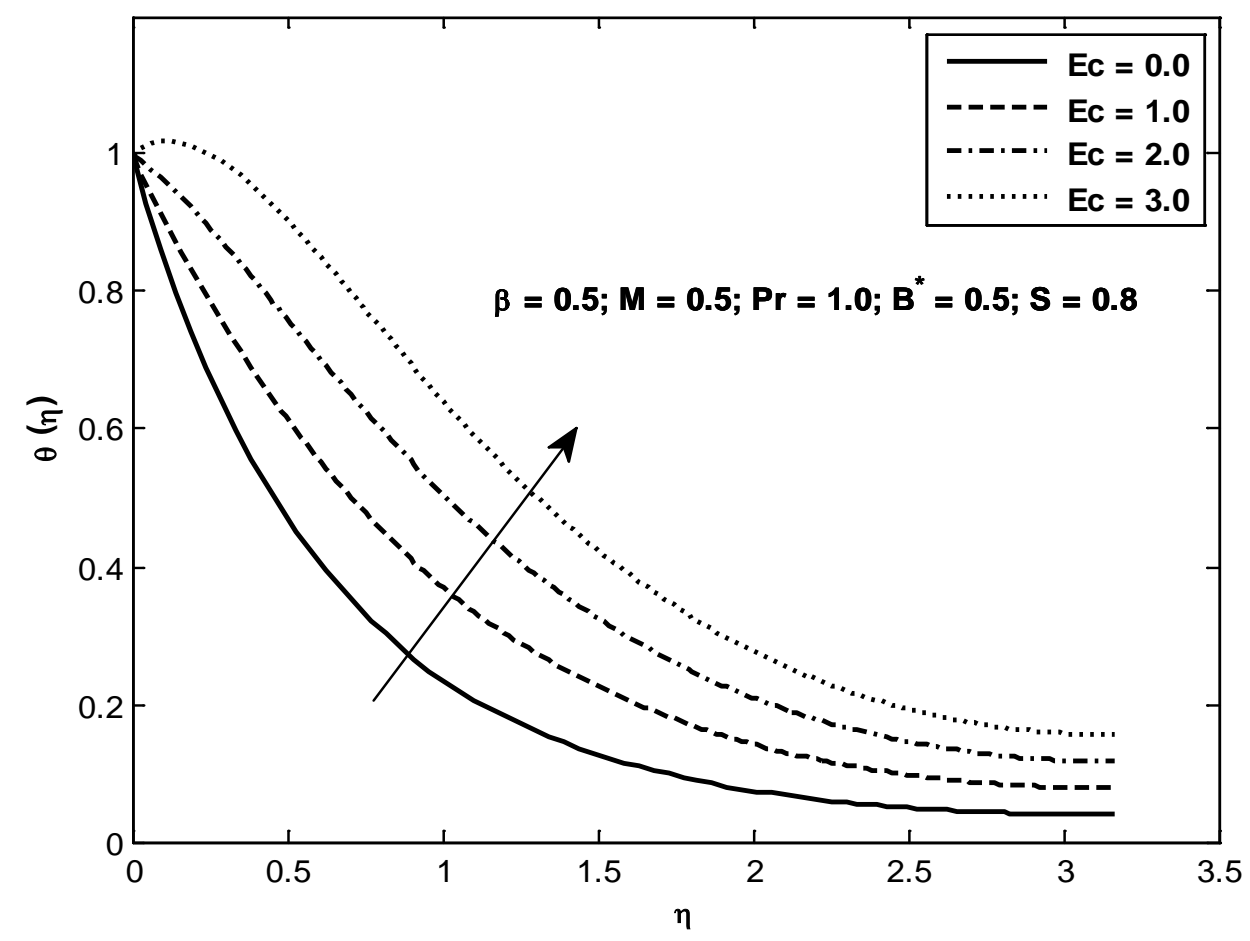

Figure 12. Temperature profiles for different values of $E c$.

in the presence of heat sink $\left(B^{*}<0\right)$ the behavior of the temperature of fluid in the film is the exact opposite of that observed in case of heat source $\left(B^{*}>0\right)$.

Surface drag coefficient and Nusselt number on the surface for different variations of 


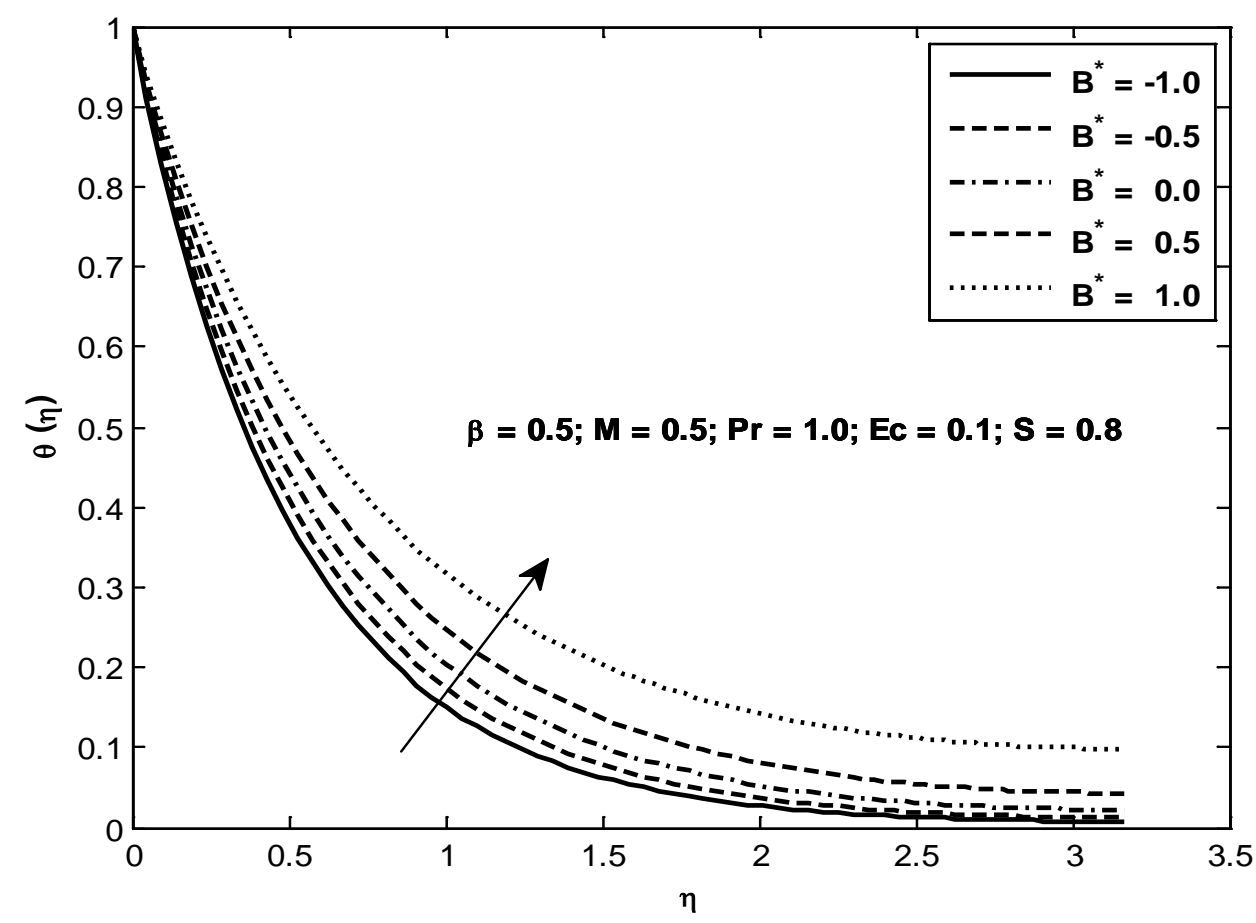

Figure 13. Temperature profiles for different values of $B^{*}$.

the flow parameters are tabulated in Table 2. Skin friction coefficient is found to enhance with elapse of time. Rate of heat transfer at the boundary is seen to decrease with increase in the unsteadiness parameter which is in conformity with the behavior of the temperature with unsteadiness parameter. Increasing values of Casson parameter reduce surface drag marginally due to smaller velocities. Rate of heat transfer is found to be small for variation in Casson parameter. Due to stronger magnetic fields the surface drag coefficient is significantly reduced. The Lorentz force is observed to favour the heat transfer. Table 3 presents the Nusselt number for different values of Pr, Ec and $B^{*}$. Increase in Prandtl number leads to an enhancement of the temperature gradient. Eckert number has a prominent impact in enhancing the rate of heat transfer.

\section{Conclusions}

In this investigation, effect of viscous dissipation and velocity slip on the characteristics of flow and heat transfer in a thin Casson liquid film resting on an unsteady stretching sheet under the influence of a uniform transverse magnetic field and thermal radiation is studied. The partial differential equations governing the flow and energy are transformed into a set of ordinary differential equations by employing appropriate similarity transformations. These ODEs are later solved numerically using shooting technique along with the efficient Runge-Kutta method. Results of the present analysis are validated with available data in literature and are found to be in excellent agreement. The following are some of the salient features of the investigation:

Film thickness is found to decrease as unsteady parameter increases. Qualitatively 
Table 2. Variation of $\left(1+\frac{1}{\beta}\right) f^{\prime \prime}(0)$ and $-\theta^{\prime}(0)$ for various values of $S, \beta$ and $M$.

\begin{tabular}{ccccc}
\hline$S$ & $\beta$ & $M$ & $\left(1+\frac{1}{\beta}\right) f^{\prime \prime}(0)$ & $-\theta^{\prime}(0)$ \\
\hline 0.8 & & & -2.473527 & 1.505621 \\
1.0 & 0.5 & 0.5 & -2.504972 & 1.592773 \\
1.2 & & & -2.478698 & 1.675480 \\
1.4 & & & -2.365328 & 1.743821 \\
& 1.0 & & -1.577477 & 1.449664 \\
0.8 & 2.0 & 0.5 & -1.585218 & 1.437879 \\
& 3.0 & & -1.591939 & 1.429346 \\
& 4.0 & & -1.596655 & 1.423580 \\
& & & & \\
& & & & \\
0.8 & 0.5 & 1.0 & -2.157798 & 1.539927 \\
& & 2.0 & -3.239791 & 1.474249 \\
& & 3.0 & -3.662303 & 1.416704 \\
\hline
\end{tabular}

Table 3. Variation of $-\theta^{\prime}(0)$ for various values of Pr, Ec and $B^{*}$.

\begin{tabular}{cccc}
\hline Pr & $E c$ & $B^{*}$ & $-\theta^{\prime}(0)$ \\
\hline 0.7 & & & 1.165108 \\
1.0 & 0.1 & 0.5 & 1.505621 \\
2.0 & & 2.298035 \\
3.0 & & 2.882486 \\
& 0.0 & & \\
& 1.0 & & 1.569157 \\
1.0 & 2.0 & 0.5 & 0.933798 \\
& 3.0 & & 0.298439 \\
& & & -0.336921 \\
& & -1.0 & 1.826436 \\
1.0 & 0.1 & -0.5 & 1.675676 \\
& & 0.5 & 1.505621 \\
& & 1.0 & 1.301671 \\
\hline
\end{tabular}

similar behavior is noticed for increasing values of magnetic field and Casson parameters.

Free surface velocity is found to be a decreasing function of the magnetic field parameter.

Temperature distribution in the thin film is enhanced with increase in magnetic field strength and non-Newtonian nature of fluid.

Viscous heating enhances rate of heat transfer.

\section{Acknowledgements}

The authors express their sincere thanks to the editor and referee for their valuable comment and suggestions, which lead to a significant improvement of the paper. 


\section{References}

[1] Rassoulinejad-Mousavi, S.M. and Abbasbandy, S. (2011) Analysis of Forced Convection in a Circular Tube Filled with a Darcy-Brinkman-Forchheimer Porous Medium Using Spectral Homotopy Analysis Method. Journal of Fluids Engineering, 133, 101207.

https://doi.org/10.1115/1.4004998

[2] Rassoulinejad-Mousavi, S.M., Hamid, R.S. and Abbasbandy, S. (2013) Heat Transfer through a Porous Saturated Channel with Permeable Walls Using Two-Equation Energy Model. Journal of Porous Media, 16, 241-254. https://doi.org/10.1615/JPorMedia.v16.i3.60

[3] Shahabeddin, K.M., Rassoulinejad-Mousavi, S.M. and Zhang, Y. (2015) Thermal Management Improvement of an Air-Cooled High-Power Lithium-Ion Battery by Embedding Metal Foam. Journal of Power Sources, 296, 305-313. https://doi.org/10.1016/j.jpowsour.2015.07.056

[4] Andersson, H.I., Aarseth, J.B., Braud, N. and Dandapat, B.S. (1996) Flow of a Power-Law Fluid Film on an Unsteady Stretching Surface. Journal of Non-Newtonian Fluid Mechanics, 62, 1-8. https://doi.org/10.1016/0377-0257(95)01392-X

[5] Usha, R. and Sridharan, R. (1993) On the Motion of a Liquid Film on an Unsteady Stretching Surface. ASME Fluids Engineering, 150, 43-48.

[6] Wang, C.Y. (1990) Liquid Film on an Unsteady Stretching Surface. Quarterly of Applied Mathematics, 48, 601-610.

[7] Dandapat, B.S., Andersson, H.I. and Aarseth, J.B. (2000) Heat Transfer in a Liquid Film on an Unsteady Stretching Surface. International Journal of Heat and Mass Transfer, 43, 6974. https://doi.org/10.1016/S0017-9310(99)00123-4

[8] Dandapat, B.S. and Ray, P.C. (1990) Film Cooling on a Rotating Disk. International Journal of Non-Linear Mechanics, 25, 569-582. https://doi.org/10.1016/0020-7462(90)90019-6

[9] Dandapat, B.S. and Ray, P.C. (1994) The Effect of Thermocapillarity on the Flow of a Thin Film on a Rotating Disc. Journal of Physics D: Applied Physics, 27, 2041-2045. https://doi.org/10.1088/0022-3727/27/10/009

[10] Gailitis, A. and Lielausis, O. (1961) On a Possibility to Reduce the Hydrodynamic Resistance of a Plate in Aelectro-Lyte. Applied Magnetohydrodynamics, 12, 143-146.

[11] Shirazpour, A., Rassoulinejad-Mousavi, S.M. and Hamid, R.S. (2011) HPM Solution of Momentum Equation for Darcy-Brinkman Model in a Parallel Plates Channel Subjected to Lorentz Force. Int. J. Mechanical, Aerospace, Mechatronic and Manufacturing Engineering, 5, 258-262.

[12] Rassoulinejad-Mousavi, S.M., Abbasbandy, S. and Alsulami, H.H. (2014) Analytical Flow of a Conducting Maxwell Fluid through a Porous Saturated Channel at Various Wall Boundary Conditions. European Physical Journal Plus, 129, 181.

https://doi.org/10.1140/epjp/i2014-14181-4

[13] Lin, Y., Zheng, L., Zhang, X., Ma, L. and Chen, G. (2015) MHD Pseudo-Plastic Nanofluid Unsteady Flow and Heat Transfer in a Finite Thin Film over Stretching Surface with Internal Heat Generation. International Journal of Heat and Mass Transfer, 84, 903-911. https://doi.org/10.1016/j.ijheatmasstransfer.2015.01.099

[14] Rassoulinejad-Mousavi, S.M. and Hessameddin, Y. (2014) Effect of Non-Linear Drag Term on Viscous Dissipation in a Fluid Saturated Porous Medium Channel with Various Boundary Conditions at Walls. Arabian Journal for Science and Engineering, 39, 1231-1240. https://doi.org/10.1007/s13369-013-0676-0

[15] Vajravelu, K., Prasad K.V. and Raju, B.T. (2013) Effects of Variable Fluid Properties on the Thin Film Flow of Ostwald-de Waele Fluid over a Stretching Surface. Journal of Hydrody- 
namics, 25, 10-19. https://doi.org/10.1016/S1001-6058(13)60333-9

[16] Abel, M.S., Mahesha, N. and Tawade, J. (2009) Heat Transfer in a Liquid Film over an Unsteady Stretching Surface with Viscous Dissipation in Presence of External Magnetic Field. Applied Mathematical Modelling, 33, 3430-3441. https://doi.org/10.1016/j.apm.2008.11.021

[17] Krishna Jyothi, P., Sreelakshmi, K., Nagendramma, V. and Sarojamma, G. (2015) Study of Thermophoresis on the MHD Flow Due to an Exponentially Stretching Sheet in the Presence of Viscous Dissipation. Procedia Engineering, 127, 340-346. https://doi.org/10.1016/j.proeng.2015.11.379

[18] Sarojamma, G., Sreelakshmi, K. and Vasundhara, B. (2016) Mathematical Model of MHD Unsteady Flow Induced by a Stretching Surface Embedded in a Rotating Casson Fluid with Thermal Radiation. 978-9-3805-4421-2/16/\$31.00_c 2016 IEEE, 1590-1595.

[19] Andersson, H.I. and Irgens, F. (1988) Gravity-Driven Laminar Film Flow of Power-Law Fluids along Vertical Walls. Journal of Non-Newtonian Fluid Mechanics, 27, 153-172. https://doi.org/10.1016/0377-0257(88)85011-0

[20] Wang, C. and Pop, I. (2006) Analysis of the Flow of a Power-Law Fluid Film on an Unsteady Stretching Surface by Means of Homotopy Analysis Method. Journal of Non-Newtonian Fluid Mechanics, 138, 161-172. https://doi.org/10.1016/j.jnnfm.2006.05.011

[21] Mahmoud, M.A.A. and Megahed, A.M. (2009) MHD Flow and Heat Transfer in a NonNewtonian Liquid Film over an Unsteady Stretching Sheet with Variable Fluid Properties. Canadian Journal of Physics, 87, 1065-1071. https://doi.org/10.1139/P09-066

[22] Chen, C.H. (2006) Effect of Viscous Dissipation on Heat Transfer in a Non-Newtonian Liquid Film over an Unsteady Stretching Sheet. Journal of Non-Newtonian Fluid Mechanics, 135, 128-135. https://doi.org/10.1016/j.jnnfm.2006.01.009

[23] Casson, N. (1959) A Flow Equation for Pigment Oil Suspensions of Printing Ink Type. In: Mil, C.C., Ed., Rheology of Dispersed System, Pergamon Press, Oxford, 84-102.

[24] Walawander, W.P., Chen, T.Y. and Cala, D.F. (1975) An Approximate Casson Fluid Model for Tube Flow of Blood. Biorheology, 12, 111-119.

[25] Tamamashi, B. (1968) Consideration of Certain Haemorheological Phenomenon from the Stand-Point of Surface Chemistry. In: Copley, A.L., Ed., Haemorheology, Pergamon Press, London, 89.

[26] Craciunescu, O.I. and Clegg, S.T. (2001) Pulsatile Blood Flow Effects on Temperature Distribution and Heat Transfer in Rigid Vessels. Journal of Biomechanical Engineering, 123, 500-505. https://doi.org/10.1115/1.1392318

[27] Weinbaun, S., Jiji, L.M. and Lemons, D.E. (1984) Theory and Experiment for the Effect of Vascular Microstructure on Surface Tissue Heat Transfer-Part I: Anatomical Foundation and Model Conceptualization. Journal of Biomechanical Engineering, 106, 321-330. https://doi.org/10.1115/1.3138501

[28] Jiji, L.M., Weinbaun, S. and Lemons, D.E. (1984) Theory and Experiment for the Effect of Vascular Microstructure on Surface Tissue Heat Transfer-Part II: Model Formulation and Solution. Journal of Biomechanical Engineering, 106, 331-341. https://doi.org/10.1115/1.3138502

[29] Cavaliere, R., Ciocatto, E.C., Giovannela, B.C., Heidelberger, C., Hojnson, R.O., Martotini, M., Rmondovi, B., Moricca, G. and Rossi-Fanelli, A. (1967) Selective Heat Sensitivity of Cancer Cells: Biochemical and Clinical Studies. Cancer, 20, 1351-1381. https://doi.org/10.1002/1097-0142(196709)20:9<1351::AID-CNCR2820200902>3.0.CO;2-\#

[30] Sarojamma, G., Ramana, B. and Vendabai, K. (2014) Heat and Mass Transfer on MHD Boundary Layer Flow of a Chemically Reacting Non-Newtonian Fluid over a Stretching 
Sheet with Suction. International Journal of Engineering Sciences \& Research Technology, 3, 197-205.

[31] Megahed, A.M. (2015) Effect of Slip Velocity on Casson Thin Film Flow and Heat Transfer Due to Unsteady Stretching Sheet in Presence of Variable Heat Flux and Viscous Dissipation. Applied Mathematics and Mechanics, 36, 1273-1284.

https://doi.org/10.1007/s10483-015-1983-9

[32] Eldabe, N.T.M. and Salwa, M.G.E. (1995) Heat Transfer of MHD Non-Newtonian Casson Fluid Flow between Two Rotating Cylinders. Journal of the Physical Society of Japan, 64, 41-64.

[33] Aziz, R.C., Hashim, I. and Alomari, A.K. (2011) Thin Film Flow and Heat Transfer on an Unsteady Stretching Sheet with Internal Heating. Meccanica, 46, 349-357.

https://doi.org/10.1007/s11012-010-9313-0

[34] Abel, M.S., Tawade, J. and Nandeppanavar, M.M. (2009) Effect of Non-Uniform Heat Source on MHD Heat Transfer in a Liquid Film over an Unsteady Stretching Sheet. International Journal of Non-Linear Mechanics, 44, 990-998.

https://doi.org/10.1016/j.ijnonlinmec.2009.07.004

Submit or recommend next manuscript to SCIRP and we will provide best service for you:

Accepting pre-submission inquiries through Email, Facebook, LinkedIn, Twitter, etc.

A wide selection of journals (inclusive of 9 subjects, more than 200 journals)

Providing 24-hour high-quality service

User-friendly online submission system

Fair and swift peer-review system

Efficient typesetting and proofreading procedure

Display of the result of downloads and visits, as well as the number of cited articles

Maximum dissemination of your research work

Submit your manuscript at: http://papersubmission.scirp.org/

Or contact ojfd@scirp.org 